\title{
Oviposition, Feeding Preferences and Distribution of Delia Species (Diptera: Anthomyiidae) in Eastern Canadian Onions
}

\author{
Julia J. Mlynarek ${ }^{1,2, * \mathbb{C} \text {, Maggie MacDonald }}{ }^{3}$, Kathrin Sim ${ }^{2}, \mathrm{Kim} \mathrm{Hiltz}^{4}$, \\ Mary Ruth McDonald ${ }^{5}$ and Suzanne Blatt ${ }^{4, *(D)}$ \\ 1 Montreal Insectarium, Montreal, QC H1X 2B2, Canada \\ 2 Harrow Research and Development Centre, Agriculture and Agri-Food Canada, Harrow, ON N0R 1G0, \\ Canada; kathrin.sim@canada.ca \\ 3 Biological Sciences, University of Alberta, Edmonton, AB T6G 2E9, Canada; mbmacdon@ualberta.ca \\ 4 Kentville Research and Development Centre, Agriculture and Agri-Food Canada, Kentville, NS B4N 1J5, \\ Canada; Kim.hiltz@canada.ca \\ 5 Department of Plant Agriculture, University of Guelph, Guelph, ON N1G 2W1, Canada; \\ mrmcdona@uoguelph.ca \\ * Correspondence: Julia.mlynarek@montreal.ca (J.J.M.); Suzanne.blatt@canada.ca (S.B.); \\ Tel.: +1-(514)-265-1871 (J.J.M.); +1-(902)-365-8552 (S.B.)
}

Received: 19 October 2020; Accepted: 8 November 2020; Published: 11 November 2020

Simple Summary: Delia root maggot species are commonly found in onions. It is unclear which species affects onions most and how they are distributed among the major onion growing regions in Eastern Canada. Through oviposition and feeding preference bioassays, we determined that all species can similarly affect onion crops. We also determined that proportions of Delia species differ between the growing regions.

\begin{abstract}
Delia antiqua, Delia platura and Delia florilega are three root maggot species commonly considered pests in Eastern Canadian onions. The onion maggot, D. antiqua, is considered the primary root maggot pest in onion but it remains unclear whether the other two species are also causing damage. In order to develop updated management strategies for root maggot, we tested adult oviposition and feeding preference by Delia larvae on four growth stages of onion using bioassays and we determined the Delia species composition across the four major onion growing regions in eastern Canada. Delia species oviposit readily on onion at the 5-7 true leaf growth stage but damage on onions is not statistically different between Delia species in our zero-inflated models. The four eastern Canadian onion growing regions have different proportions of Delia species. Southern Ontario and Quebec were the only two regions where Delia antiqua was collected. The highest average numbers of Delia spp. were caught in Quebec and Nova Scotia. Our study shows that timing is important in implementation of management strategies for root maggot in Eastern Canadian onions.
\end{abstract}

Keywords: root maggot; Allium; bioassay; community

\section{Introduction}

Canadian field vegetable and field crops can be host to several damaging root maggot species in the genus Delia Robideau-Desvoidy (Diptera: Anthomyiidae) [1]. The two most studied pests are specialist species: Delia radicum (Linnaeus), the cabbage maggot, and Delia antiqua (Meigen), the onion maggot. Delia radicum feeds on members of the Brassiceae [2,3] while D. antiqua feeds on various Allium species. Other species within the genus, e.g., Delia platura (Meigen), the seedcorn maggot, and Delia 
florilega (Zetterstedt), the bean seed maggot, are considered generalists. Delia platura can develop on over 40 host plants in multiple families [4,5]. Delia florilega is polyphagous with the ability to feed and develop on legumes, garden crops and cereals $[4,6]$.

Three Delia species are commonly associated with onion crops: D. antiqua, D. platura and D. florilega [1]. Larvae of Delia spp. damage plants by feeding on the germinating seeds, seedlings and, if conditions are right, can even mine the stems, rendering the plants unmarketable. Losses of untreated onion plants attributed to $D$. antiqua feeding can average $24-40 \%$ in Canada, depending upon variety [1]. Although $D$. antiqua is considered the primary pest of onions, studies have shown that D. platura and D. florilega may be causing a larger proportion of damage to onion bulbs than previously thought [7-10]. Certain studies, based on field observations, even suggest that $D$. platura and $D$. florilega may be primary invaders in onion $[6,11]$.

Current management strategies targeting root maggots in eastern Canadian onion crops include chemical, cultural and biological controls, but are applied non-discriminately to all species of Delia maggots. Insecticides (usually cyromazine or chlorpyrifos) are commonly applied at seeding to control the first generation of root maggots in the spring; however, $D$. antiqua has been showing signs of resistance to chlorpyrifos [10,12]. This insecticide will no longer be available in Canada after 2020. Insecticide seed treatments are now available, but are applied prior to seeding, and also may affect all species of Delia whether they attack onions or not. Cultural controls such as appropriate crop rotation and timed planting potentially control root maggot populations [13], however crop rotation is not a feasible option in many of the intensive onion production regions of Canada. Biological controls measures such as entomopathogenic nematodes and fungi [14-16] may reduce root maggot damage. These strategies are used singly or in combination to reduce Delia pest pressure [13].

Even with multiple Integrated Pest Management (IPM) tools available to control root maggots, the probability of success is affected by the lack of knowledge about the species that are causing damage to the crops. The main objectives of our research were to use bioassays to (a) elucidate female preference to lay eggs at particular plant growth stages (hereafter oviposition), (b) determine feeding preference to identify which species actively damages onion and at what growth stage and (c) determine the diversity and distribution of Delia species in eastern Canadian onion growing regions (Nova Scotia, Quebec and Ontario). The combination of these will hopefully provide insight into management strategies for root maggots in onion.

\section{Materials and Methods}

\subsection{Study Species}

Delia antiqua and D. platura puparia were obtained from London Research and Development Centre (London, ON, Canada) and Montmorency College (Laval, QC, Quebec), respectively. Delia florilega was not included into the bioassays because we could not obtain or establish a laboratory colony for that species. Delia species were reared for one generation on an artificial diet as described in Ishikawa et al. [17] and, following Silver et al. [18], maintained in a growth chamber at $22{ }^{\circ} \mathrm{C}$ with $70 \%$ humidity and a photoperiod of 18:6, Light:Dark, at the Kentville Research and Development Centre (Agriculture and Agri-Food Canada).

Onion seed of Allium cepa cv. (LaSalle) was obtained from Stokes Seed, Thorold, Ontario, and sowed in plastic pots $(4 \mathrm{~cm}$ diameter) with a standard greenhouse potting mix, watered as needed and maintained in the same growth chamber with the Delia colonies. When plants reached one of 4 different plant growth stages: (1) 5 days post seeding, (2) radical/flag leaf stage, (3) second true leaf stage (TLS) and (4) 5-7th true leaf stage (TLS), they were used in bioassays. The plant stages 2 through 4 lasted on average four days each. 


\subsection{Bioassays}

\subsubsection{Oviposition Preference}

For each replicate, one mating pair (approximately 48-96 h old) was introduced into a BugDorm-1 (BioQuip Products, Rancho Dominguez, CA, USA) with one onion plant for $48 \mathrm{~h}$ with 20 replicates for each growth stage and species combination. We chose 48-96 h old mating couples because that length of time allowed us to be certain that the females were mated and that they have not started laying yet. The plant was then destructively examined under a microscope for the number and placement of eggs (Supplementary Table S1).

\subsubsection{Feeding Preference}

Onion plants were inoculated with zero, one or three D. antiqua or D. platura larvae, which had hatched 24-36 h prior to the assay, at the specific plant growth stages, with 20 replicates for each density and root maggot species. Larvae remained in pots until pupae or adult flies were recovered. Once the plants reached the bulb stage, they were assessed for damage (i.e., marketability; Supplementary Table S2). The damage rating was assessed on a scale from 0 to 5 based on an altered Dosdall's scale [19] and grouped based on rating. Samples with ratings between 0 and 1 were deemed marketable, and ratings from 2 to 5 were deemed unmarketable. A control with no larval inoculation was also done, but these were not included in the analyses because no damage was observed in these controls.

\subsubsection{Statistical Analyses}

The data for the oviposition bioassay was over-dispersed (variance $=57.16>$ mean $=3.61$ ) with an excess of zeros (76.3\% zero counts) so we fitted a Zero-Inflated Generalized Linear Model with Negative Binomial distribution (ZINB) with plant growth stage and Delia species as explanatory variables and number of eggs laid as the response variable. It was the best-fit model compared with a Zero-Inflated Generalized Linear Model with Poisson distribution (ZIP) using Akaike Criterion (AIC) (ZIP AIC score 387.49 and ZINB AIC score 326.21).

Similarly, for the damage bioassays, the data were over-dispersed (variance $=4.75>$ mean $=1.89$ ) with an excess of zeros (46.9\% zero counts). We fitted a ZIP Model with plant growth, larval density and Delia species as explanatory variables and mean damage rating as the response. It was the best-fit model when compared with a ZINB using AIC (ZIP AIC score 1031.18 vs. ZINB AIC score 1033.18).

All statistics were done with the pscl package [20,21] in RStudio [22].

\subsection{Distribution}

\subsubsection{Study Sites and Sampling}

The study was conducted in four regions (Figure 1) with six sites in Nova Scotia $\left(45.0^{\circ} \mathrm{N}, 64.5^{\circ} \mathrm{W}\right.$; average precipitation 47.01), five sites in Southwestern Quebec $\left(45.4^{\circ} \mathrm{N}, 73.2^{\circ} \mathrm{W}\right.$; average precipitation $82.85 \mathrm{~mm}$ ), six sites at the Muck Research Station, University of Guelph in the Holland marsh, Ontario (44.1 ${ }^{\circ} \mathrm{N}, 79.5^{\circ} \mathrm{W}$; average precipitation 99.32) and five sites in the Southwestern region of Chatham-Kent County, Ontario $\left(42.3^{\circ} \mathrm{N}, 82.5^{\circ} \mathrm{W}\right.$; average precipitation $\left.11.67 \mathrm{~mm}\right)$. At each site, four dry-touch blue sticky cards (Solida, QC, USA), measuring $9.5 \times 12.5 \mathrm{~cm}$, were placed facing into the field on the edge of the crop a meter from the ground to collect adult Delia species flying through the field. We used blue sticky cards because that is the color of sticky card used by Canadian growers to monitor for onion maggot. These sticky cards were changed twice a weekly from planting (late May) through to harvest (late July) in 2017 (Supplementary Table S3). We also pulled wilted onion plants and collected soil around those onions to verify for maggots. However, no maggots were found. 


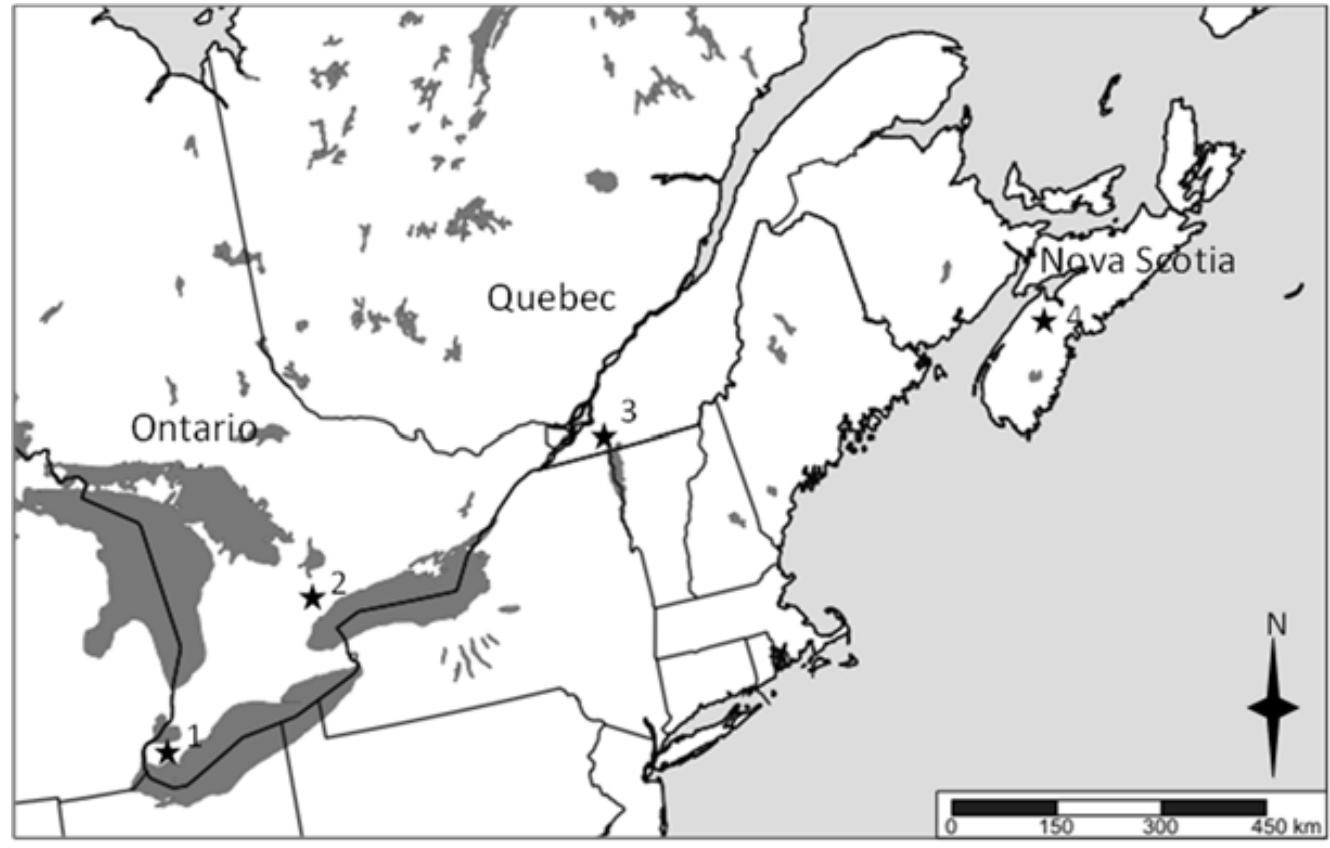

Figure 1. Main onion growing regions in Canada. Regions denoted by stars: 1 -Southwestern Ontario, 2-Southern Ontario, 3-Quebec, 4-Nova Scotia.

Once the sticky cards were collected, they were returned to the laboratory. Delia species from the sticky traps were identified using the key provided by Savage et al. [6]. A subset of the sticky cards was sent to Bishop's University for verification of species identity. A few specimens were removed from traps, mounted and deposited at the Canadian National collection as vouchers. Only males were identified because females of $D$. platura and $D$. florilega cannot be reliably distinguished morphologically, especially from sticky cards. Identification of female Delia relies on bristles on legs and other easily distorted or characters that can be broken.

\subsubsection{Statistical Analyses}

For each region, the data were pooled over the entire season since there was little difference in diversity of Delia within each region. Spatial autocorrelation was tested using the Mantel test and a Permutational Multivariate Analysis of Variance (PermANOVA) based on Bray-Curtis distance matrix was used to determine significant differences among Delia species assemblages by region using the function Adonis. All statistics were run with the vegan R package [23] in RStudio [22].

\section{Results}

\subsection{Bioassays}

\subsubsection{Oviposition Preference}

Eggs were deposited around the base of the plant or in the crevices of the plant and in some cases, both. This was consistent for all the bioassays. Only the Radical/flag plant growth stage $(\mathrm{F}=3.29$; $p<0.01$ ) showed a significant difference with respect to ovipositional preference in the zero-inflation portion of the models (Table 1). It must also be noted that Delia platura did not oviposit on onions at any plant stage during the tested $48 \mathrm{~h}$ exposure. 
Table 1. Results of Zero-Inflated Generalized Linear Model with Negative Binomial distribution (ZINB) testing for oviposition preference between onion plant growth stage, Delia larval density and Delia species for damage to the onion plants.

\begin{tabular}{cccc}
\hline Count Model Coefficients & & & \\
\hline Factors & Coefficient Estimate & Std Error & $p$ \\
\hline Intercept & 2.74 & 0.14 & $<0.01$ \\
Species & -0.69 & 0.61 & 0.25 \\
Growth (5-7 TL) & 0.03 & 0.18 & 0.88 \\
Growth (germ) & $-6.96 \times 10^{-10}$ & $\mathrm{NA}$ & $\mathrm{NA}$ \\
Growth (rad/flag) & -0.49 & 0.43 & 0.26 \\
Log (Theta) & 1.49 & 0.31 & $<0.01$ \\
\hline Zero-inflated coefficients & & & \\
\hline Intercept & -1.10 & 0.52 & 0.03 \\
Species & 22.84 & 4347.31 & 0.99 \\
Growth (5-7 TL) & -18.79 & 4347.31 & 0.99 \\
Growth (germ) & 21.53 & 6095.67 & 0.99 \\
Growth (rad/flag) & 3.29 & 0.90 & $<0.01$ \\
\hline
\end{tabular}

\subsubsection{Feeding Preference}

The significantly different factors in the Poisson count model portion are species $(\mathrm{F}=-1.26 ; p<0.01)$ and $5-7$ TL growth stage $(\mathrm{F}=-0.31 ; p<0.01)$. A single $D$. antiqua caused onion to be non-marketable (mean damage rating of 3) when fed upon at the 5-7 TL stage. With 3 larvae, the damage rating increased to 4 (Figure 2). Delia platura caused some damage to onion when feeding on the radical/flag plant growth stage with a damage rating of 2 . Feeding by D. platura on any other plant growth stage caused only minimal damage. There are no significant factors in the zero-inflation portion of the model (Table 2).

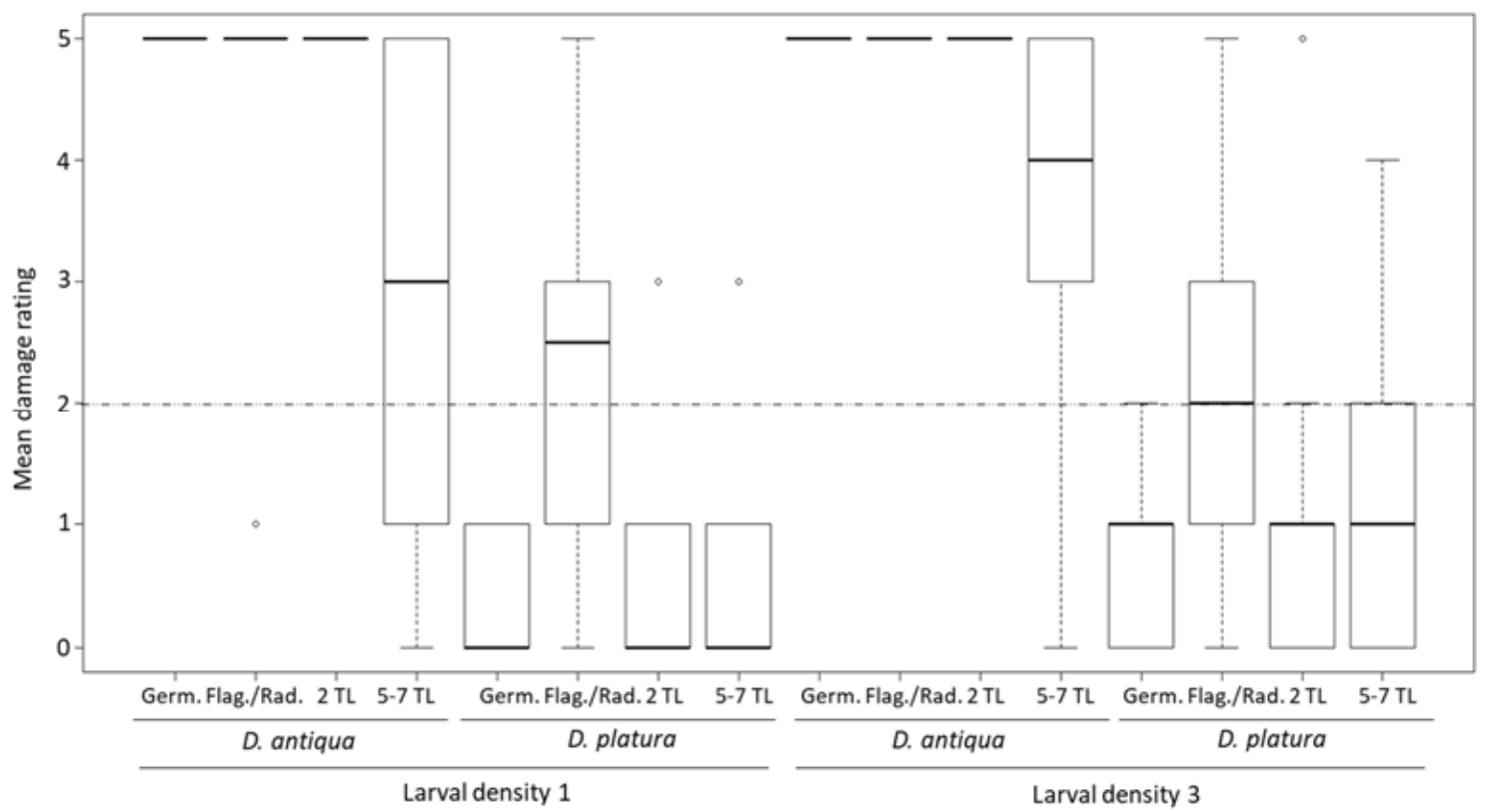

Figure 2. Feeding damage assessment across plant growth stages, and Delia species when inoculated with 1 or 3 Delia larvae in growth chamber experiments. Dotted line at 2 denotes the limit of marketability (below is marketable, above is unmarketable). 
Table 2. Results of Zero-Inflated Generalized Linear Model with Poisson distribution (ZIP) testing for feeding preference differences between onion plant growth stage, Delia larval density and Delia species for damage to the onion plants.

\begin{tabular}{cccc}
\hline Count Model Coefficients & & & \\
\hline Factors & Coefficient Estimate & Std Error & $p$ \\
\hline Intercept & 1.49 & 0.10 & $<0.01$ \\
Species & -1.26 & 0.09 & $<0.01$ \\
Growth (5-7 TL) & -0.31 & 0.10 & $<0.01$ \\
Growth (germ) & -0.01 & 0.10 & 0.91 \\
Growth (rad/flag) & 0.15 & 0.09 & 0.09 \\
Ldensity & 0.03 & 0.03 & 0.42 \\
\hline Zero-inflated coefficients & & & \\
\hline Intercept & 20.64 & 69.72 & 0.77 \\
Species & 10.50 & 65.18 & 0.87 \\
Growth (5-7 TL) & -0.42 & 1.01 & 0.68 \\
Growth (germ) & 0.55 & 0.85 & 0.52 \\
Growth (rad/flag) & -10.28 & 57.18 & 0.86 \\
Ldensity & -31.35 & 95.44 & 0.74 \\
\hline
\end{tabular}

\subsection{Distribution of Delia}

Nova Scotia and Quebec had the highest number of adult Delia flies followed by Southern Ontario and Southwestern Ontario (Figure 3), but only Quebec and Southern Ontario had D. antiqua. Delia platura was the most common species in all regions. These differences in composition were statistically significant (PerMANOVA Adonis $\mathrm{R}^{2}=0.50, p<0.05$ ). The Mantel test showed that spatial distance between the regions is not auto correlated with Delia diversity $(\mathrm{r}=0.47 ; p=0.001)$. Delia species composition is more similar within regions then between regions (Figure 3).

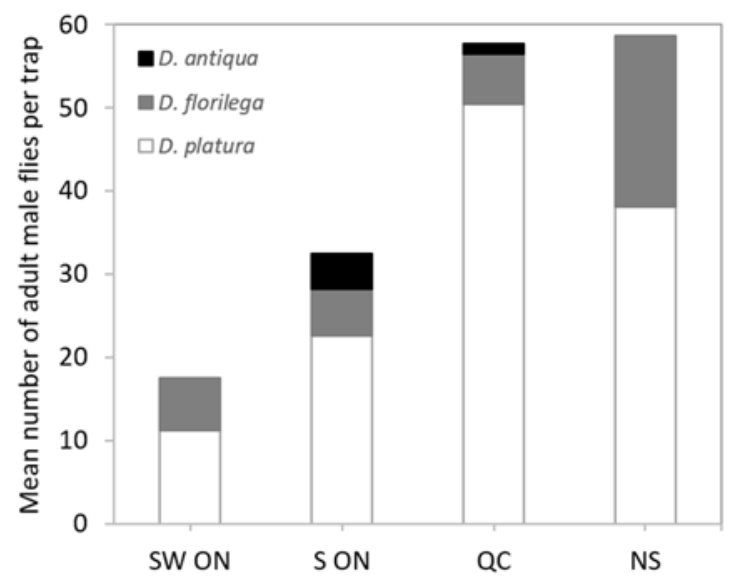

Figure 3. Mean number (for the collecting period) of adult male Delia species collected from blue sticky cards in four major onion growing regions of Canada.

\section{Discussion}

This study shows some interesting results about the relative oviposition preference and damage to onions seedlings and bulbs caused by Delia root feeding maggots in eastern Canada. Both Delia spp. were found to be capable of causing economic damage to onions in laboratory bioassays, even when only a single larva was present, highlighting the risk root maggot species present.

Delia antiqua favor older onion plants for oviposition. This is in contrast with past studies and beliefs when it was widely thought that most oviposition occurs when onion plants are seedlings and most vulnerable [1] and foliar insecticide sprays of diazinon or chlorpyrifos to protect bunching onions 
are applied to seedlings in the spring. The variation in oviposition preference suggests management strategies should focus on monitoring for Delia adult population size when the onions are planted, followed by insecticide treatments when the onions are a little older.

Our results are consistent with those of Harris and Miller [24], who found that onion flies were most attracted to upright cylinders 2-12 $\mathrm{mm}$ in diameter, and oviposited seven times more on $15 \mathrm{~cm}$ high cylinders as compared to $2 \mathrm{~cm}$. Our results are also consistent with Mowry [25] as oviposition was low on young onion seedlings. When given the choice of a seedling or a sprouted onion bulb, female $D$. antiqua deposited 60-200 times more eggs on the sprouted bulb than the seedling [25]. Ovipositing females choose the host plant and they must be able to recognize the suitability of the host plant for the development of their progeny. Dindonis and Miller [26] found decomposing onion seedlings and bulbs to elicit a greater host finding response by female D. antiqua than healthy plants. Healthy bulbing plants caught significantly fewer $D$. antiqua females than their decomposing counterparts, with healthy seedlings eliciting a response comparable to that of the decomposing seedlings. Preference for the decomposing onion may further be advantageous for larval survival due to easier larval penetration of onion bulbs and efficient larval development [26]. Monitoring and removing non-healthy onions will help reduce Delia spp. pressure by reducing oviposition.

Delia platura is a generalist and our results show that they are not significantly different from D. antiqua in their likelihood of feeding on onion. However, we noted that the adult D. platura do not oviposit eggs on onions, and, based on our observations, the larvae do not survive when they have to feed on onions. This is consistent with work on this species in other cropping systems: females oviposit into fields with decaying organic matter and the larva are attracted to germinating seedlings [27]. These results counter, in part, observations where D. platura is a serious pest of onion in California [10] and in the UK [11]. These findings are supported by experiments demonstrating that D. platura prefer decomposing onions [26], which could explain the ubiquitous nature of D. platura in the Canadian onion fields surveyed. Delia platura could be feeding on damaged and decomposing onions as well as other plants within the onion fields. As D. platura appears to be a lower risk pest, growers in Eastern Canada should focus on managing D. antiqua. This is contrary to other studies, and general knowledge, where D. platura is reported as a serious pest in onion in other regions $[10,11]$. The lack of D. platura impact on onion by populations from Nova Scotia and Quebec suggests there may be population genetic differences within the species or different environmental conditions to become an economic pest in some regions, e.g., California and the UK, but not others.

The community composition of Delia differs among the Eastern Canadian growing regions, and some regions are at a low risk of infestation by D. antiqua. The distribution survey found the main onion growing regions of Eastern Canadian to have different proportions of the three common Delia species. Southern Ontario had the highest proportion of D. antiqua followed by Quebec, while Nova Scotia and Southwestern Ontario did not have any D. antiqua. Delia platura was common on sticky traps in all regions but Nova Scotia and Quebec had higher proportions of that species when compared with Ontario. Differences in presence of $D$. antiqua are potentially due to field management, especially crop rotation [13], and the evolution of resistance [12]. Delia antiqua was collected only in Southern Ontario and Quebec, two regions where fields are intensely cultivated for onions year after year, and have been for at least eight decades, leading to similar population variability as suggested by Lamb and Boivin [28]. In Southern Ontario, growers generally alternate between onions and carrots primarily, and sometimes celery or another root vegetable is added to the rotation (Cranmer personal communication Ontario Ministry of Agriculture, Food and Rural Affairs (OMAFRA)). The rotations are similar in Quebec, but radishes and leafy greens may be added to their rotations (Van Dyk, personal communication OMAFRA). In Nova Scotia, onion crops are rotated intensely using a 7-year rotation from an onion crop to several non-allium crops, while in Southwestern Ontario, onion fields are in rotation frequently, but tend to space fields at large distances (at least $10 \mathrm{~km}$ ) from one another from one year to another (Mlynarek personal observation Agriculture and Agr-Food Canada (AAFC)). Martinson et al. [29] concluded that long-range directed movement has little influence on success of colonization, but we 
believe in the case of Southwestern Ontario and Nova Scotia, the distance may just be too great between fields and years for the Delia antiqua to locate fields of onions. These types of host-non-host, large distance rotations change the communities of Delia spp. in the field where a specialist like Delia antiqua will not be present but generalists like D. platura and D. florilega are more abundant.

There are two main caveats of our exploration of the diversity and distribution of Delia species. We only measured the presence of males of each species of D. platura and D. florilega as females are more difficult, or impossible to confidently differentiate using morphological characters. Additionally, identification of Delia females relies on the number and position of bristles on the legs and thorax, which can be lost or damaged on sticky cards, leading to misidentifications [6]. The second caveat also has to do with our study solely focusing on assessing populations and diversity using sticky cards traps. We must reiterate at this point that we removed wilted looking plants and shifted soil around those plants to check for maggots, but did not find any. Sticky cards are the standard trapping method used by growers to scout Delia populations, and we employed them for our surveys, but they may not be the best trapping method. Broatch and Vernon [30] showed that pan traps collect more intact specimens than sticky cards. Delia antiqua is more attracted to yellow, rather than blue traps, but the use of yellow sticky cards in this study would only increase the numbers of D. antiqua and decrease the numbers of other Delia species trapped. Additionally, we cannot be sure that sticky trap catches accurately reflect larval populations in bulbs, or just reflect diversity of insects flying through the environment.

Further research to develop management strategies focused on Delia is needed for Eastern Canadian onion crops in line with the ones proposed by Vernon et al. [31]. Delia antiqua has developed resistance to some insecticides [12]. There is a need to reduce insecticide use, and to identify new modes of action to manage this pest. Some of the new seed treatments are used at very low rates per hectare and do not target the third generation of onion flies, so may reduce the risk of insecticide resistance. An integrated pest management approach is desirable, with combinations of chemical, biological and cultural methods, and crop rotations [13] where possible. Intercropping [32] can be effective for small or organic production systems. Delayed planting [33] can be effective for short-season onions or bunching onions but is not always practical for bulb onion production.

\section{Conclusions}

Through these findings, we suggest a three-fold approach to managing Delia spp.: (1) monitoring for Delia spp. should focus early in the planting season to determine if management of the crop is necessary before the vulnerable growth stage (5-7 TL), (2) monitoring and pulling non-healthy young onion plants to discourage Delia spp. from ovipositing and populations growing and (3) managing the field with chemical or biocontrol should focus when the plants are near a 5 TL stage if the Delia spp. populations are high. In order to prevent damage in onions by Delia spp. root maggots, biological control methods $[11,14,15]$ should be researched.

Supplementary Materials: The following are available online at http://www.mdpi.com/2075-4450/11/11/780/s1, Table S1: Raw data for the Delia oviposition bioassay, Table S2: Delia feeding preference bioassay, Table S3: Raw data Delia distribution.

Author Contributions: Conceptualization, J.J.M. and S.B.; methodology, J.J.M., K.S., M.M., and S.B.; validation, J.J.M.; formal analysis, M.M. and J.J.M.; investigation, S.B. and J.J.M.; resources, J.J.M. and S.B.; writing-original draft preparation, MM., K.S., K.H., and S.B.; writing-review and editing, M.R.M., J.J.M., and S.B.; visualization, J.J.M. and S.B.; supervision, S.B.; project administration, S.B. and J.J.M.; funding acquisition, S.B. and J.J.M. All authors have read and agreed to the published version of the manuscript.

Funding: This research received no external funding.

Acknowledgments: We thank J. Savage, Bishop's University, for identifications, Anne-Marie Fortier, PRISME/Phytodata, for the Quebec data, François Fournier, Montmorency College, for providing the Delia pupa for the bioassays, and Kathryn Makela and the Pest Management Centre (Projects J-000031, J-001575 and J-001819) for facilitating the project.

Conflicts of Interest: The authors declare no conflict of interest. 


\section{References}

1. Finch, S. Ecological considerations in the management of Delia pest species in vegetable crops. Annu. Rev. Entomol. 1989, 34, 117-137. [CrossRef]

2. Griffiths, G. Flies of the Nearctic Region. Cyclorrhapha II (Schizophora: Calyptrate) Anthomyiidae; Volume VIII, Part 2, Number 7; Schweizerbartsche Verlagbuchhandlung: Stuttgart, Germany, 1991.

3. Howard, R.J.; Garland, J.A.; Seaman, W.L.; Grafius, E.J. Diseases and pests of vegetable crops in Canada. J. Econ. Entomol. 1996, 89, 1045.

4. Griffiths, G. Flies of the Nearctic Region. Cyclorrhapha II (Schizophora: Calyptratae) Anthomyiidae, Volume III, Part 2, Number 11; Schweizerbartsche Verlagsbuchhandlung: Stuttgart, Germany, 1993.

5. Guerra, P.C.; Keil, C.B.; Stevenson, P.C.; Mina, D.; Samaniego, S.; Peralta, E.; Mazon, N.; Chancellor, T.C.B. Larval Performance and Adult Attraction of Delia platura (Diptera: Anthomyiidae) in a Native and an Introduced Crop. J. Econ. Entomol. 2016, 110, 186-191.

6. Savage, J.; Fortier, A.-M.; Fournier, F.; Bellavance, V. Identification of Delia pest species (Diptera: Anthomyiidae) in cultivated crucifers and other vegetable crops in Canada. Can. J. Arthropod Identif. 2016, 29, 1-40.

7. Merrill, L.G., Jr. Diptera reared from Michigan onions growing from seed. J. Econ. Entomol. 1951, 44, 1015. [CrossRef]

8. Merrill, L.G., Jr;; Hutson, R.J.J. Maggots attacking Michigan onions. J. Econ. Entomol. 1953, 46, 678-680. [CrossRef]

9. Finlayson, D.J.J. Maggots and puparia in stems and seed balls of onions at harvest. J. Econ. Entomol. 1956, 49, 460-462. [CrossRef]

10. Wilson, R.G.; Orloff, S.B.; Taylor, A.G. Evaluation of insecticides and application methods to protect onions from onion maggot, Delia antiqua, and seedcorn maggot, Delia platura, damage. Crop Prot. 2015, 67, 102-108. [CrossRef]

11. Ellis, S.A.; Scatcherd, J.E. Bean seed fly (Delia platura, Delia florilega) and onion fly (Delia antiqua) incidence in England and an evaluation of chemical and biological control options. Ann. Appl. Biol. 2007, 151, 259-267. [CrossRef]

12. Nault, B.A.; Zhao, J.-Z.; Straub, R.W.; Nyrop, J.P.; Hessney, M.L. Onion Maggot (Diptera: Anthomyiidae) Resistance to Chlorpyrifos in New York Onion Fields. J. Econ. Entomol. 2006, 99, 1375-1380. [CrossRef]

13. Walters, T.; Eckenrode, C.J.J. Integrated management of the onion maggot (Diptera: Anthomyiidae). J. Econ. Entomol. 1996, 89, 1582-1586. [CrossRef]

14. Carruthers, R.I.; Haynes, D.L. Laboratory transmission and in vivo incubation of Entomophthora muscae (Entomophthorales: Entomophthoracae) in the onion fly, Delia antiqua (Diptera: Anthomyiidae). J. Invertebr. Pathol. 1985, 45, 282-287. [CrossRef]

15. Carruthers, R.I.; Haynes, D.L.; MacLeod, D.M. Entomophthora muscae (Entomophthorales: Entomophthoracae) mycosis in the onion fly, Delia antiqua (Diptera: Anthomyiidae). J. Invertebr. Pathol. 1985, 45, 81-93. [CrossRef]

16. Davidson, G.; Chandler, D.J.J. Laboratory evaluation of entomopathogenic fungi against larvae and adults of onion maggot (Diptera: Anthomyiidae). J. Econ. Entomol. 2005, 98, 1848-1855. [CrossRef] [PubMed]

17. Ishikawa, Y.; Tsukada, S.; Matsumoto, Y. Effect of Temperature and Photoperiod on the Larval Development and Diapause Induction in the Onion Fly, Hylemya antiqua Meigen: Diptera: Anthomyiidae. Appl. Entomol. Zool. 1987, 22, 610-616. [CrossRef]

18. Silver, N.; Hillier, K.; Blatt, S. Management of Delia (Diptera: Anthomyiidae) through selectively timed planting of Phaseolus vulgaris (Fabaceae) in Atlantic Canada. Can. Entomol. 2018, 150, 663-674. [CrossRef]

19. Dosdall, L.M.; Herbut, M.J.; Cowle, N.T. Susceptibilities of species and cultivars of canola and mustard to infestation by root maggots (Delia spp.) (Diptera: Anthomyiidae). Can. Entomol. 1994, 126, 251-260. [CrossRef]

20. Zeileis, A.; Kleiber, C.; Jackman, S. Regression Models for Count Data in R. J. Stat. Softw. 2008, $27,27$. Available online: http://www.jstatsoft.org/v27/i08/ (accessed on 25 August 2020). [CrossRef]

21. Jackman, S. Pscl: Classes and Methods for R Developed in the Political Science Computational Laboratory, R package version 1.5.5; United States Studies Centre, University of Sydney: Sydney, Australia, 2020; Available online: https://github.com/atahk/pscl/ (accessed on 25 August 2020).

22. RStudio Team. Integrated Development for R.; RStudio, Inc.: Boston, MA, USA, 2015; Available online: http://www.rstudio.com/ (accessed on 25 August 2020). 
23. Oksanen, J.; Blanchet, F.G.; Friendly, M.; Kindt, R.; Legendre, P.; McGlinn, D.; Minchin, R.B.; O’hara, R.; Simpson, G.L.; Solymos, P.; et al. Vegan: Community Ecology Package; R package version 2.5-6; 2019. Available online: https://cran.r-project.org/web/packages/vegan/index.html (accessed on 25 August 2020).

24. Harris, M.O.; Miller, J.R. Foliar form influences ovipositional behaviour of the onion fly. Physiol. Entomol. 1984, 9, 145-155. [CrossRef]

25. Mowry, T.M. Ovipositional patterns and larval movement of Delia antiqua (Diptera: Anthomyiidae) on sprouted bulb and seedling onions. J. Econ. Entomol. 1993, 86, 1440-1445. [CrossRef]

26. Dindonis, L.L.; Miller, J.R. Host-finding responses of onion and seedcorn flies to healthy and decomposing onions and several synthetic constituents of onion. Environ. Entomol. 1980, 9, 467-472. [CrossRef]

27. Eckenrode, C.J.; Harman, G.E.; Webb, D.R. Seed-borne microorganisms stimulate seedcorn maggot egg laying. Nature 1975, 256, 487-488. [CrossRef]

28. Lamb, R.J.; Boivin, G. Population variability of the three Delia species (Diptera: Anthomyiidae) from the same agricultural habitat in Quebec, Canada. Can. Entomol. 2018, 150, 80-86. [CrossRef]

29. Martinson, T.; Nyrop, J.; Eckenrode, C.J.J. Dispersal of the onion fly (Diptera: Anthomyiidae) and larval damage in rotated onion fields. J. Econ. Entomol. 1988, 81, 508-514. [CrossRef]

30. Broatch, J.S.; Vernon, R.S. Comparison of water pan traps and sticky traps fpr monitoring Delia spp. (Diptera: Anthomyiidae) in canola. Can. Entomol. 1997, 129, 979-984. [CrossRef]

31. Vernon, R.S.; Judd, G.J.R.; Borden, J.H. Commercial monitoring programme for the onion fly, Delia antiqua (Meigen) (Diptera: Anthomyiidae) in south-western British Columbia. Crop Prot. 1987, 6, 304-312. [CrossRef]

32. Hummel, J.D.; Dosdall, L.M.; Clayton, G.W.; Harker, K.N.; O’Donovan, J.T. Effects of Canola-Wheat Intercrops on Delia spp. (Diptera: Anthomyiidae) Oviposition, Larval Feeding Damage, and Adult Abundance. J. Econ. Entomol. 2009, 102, 219-228. [CrossRef]

33. Nault, B.A.; Werling, B.P.; Straub, R.W.; Nyrop, J.P. Delaying Onion Planting to Control Onion Maggot (Diptera: Anthomyiidae): Efficacy and Underlying Mechanisms. J. Econ. Entomol. 2011, 104, 1622-1632. [CrossRef]

Publisher's Note: MDPI stays neutral with regard to jurisdictional claims in published maps and institutional affiliations.

(C) 2020 by the authors. Licensee MDPI, Basel, Switzerland. This article is an open access article distributed under the terms and conditions of the Creative Commons Attribution (CC BY) license (http://creativecommons.org/licenses/by/4.0/). 